This item was submitted to Loughborough's Research Repository by the author.

Items in Figshare are protected by copyright, with all rights reserved, unless otherwise indicated.

\title{
Experimental and computational study of vehicle surface contamination on a generic bluff body
}

\section{PLEASE CITE THE PUBLISHED VERSION}

http://dx.doi.org/10.4271/2016-01-1604

\section{PUBLISHER}

(C) SAE International

\section{VERSION}

VoR (Version of Record)

\section{PUBLISHER STATEMENT}

This work is made available according to the conditions of the Creative Commons Attribution-NonCommercialNoDerivatives 4.0 International (CC BY-NC-ND 4.0) licence. Full details of this licence are available at: https://creativecommons.org/licenses/by-nc-nd/4.0/

\section{LICENCE}

CC BY-NC-ND 4.0

\section{REPOSITORY RECORD}

Kabanovs, Anton, Max Varney, Andrew Garmory, Martin A. Passmore, and Adrian P. Gaylard. 2016. "Experimental and Computational Study of Vehicle Surface Contamination on a Generic Bluff Body". figshare. https://hdl.handle.net/2134/21528. 


\section{Experimental and Computational Study of Vehicle Surface Contamination on a Generic Bluff Body}

\section{Anton Kabanovs, Max Varney, Andrew Garmory, and Martin Passmore}

Loughborough University

\section{Adrian Gaylard}

Jaguar Land Rover

CITATION: Kabanovs, A., Varney, M., Garmory, A., Passmore, M. et al., "Experimental and Computational Study of Vehicle Surface Contamination on a Generic Bluff Body," SAE Technical Paper 2016-01-1604, 2016, doi:10.4271/2016-01-1604.

Copyright (C) 2016 SAE International

\begin{abstract}
This paper focuses on methods used to model vehicle surface contamination arising as a result of rear wake aerodynamics. Besides being unsightly, contamination, such as self-soiling from rear tyre spray, can degrade the performance of lighting, rear view cameras and obstruct visibility through windows. In order to accurately predict likely contamination patterns, it is necessary to consider the aerodynamics and multiphase spray processes together. This paper presents an experimental and numerical (CFD) investigation of the phenomenon.
\end{abstract}

The experimental study investigates contamination with controlled conditions in a wind tunnel using a generic bluff body (the Windsor model.) Contamination is represented by a water spray located beneath the rear of the vehicle. The aim is to investigate the fundamentals of contamination in a case where both flow field and contamination patterns can be measured, and also to provide validation of modelling techniques in a case where flow and spray conditions are known.

CFD results were obtained using both steady RANS and unsteady URANS solvers, combined with particle tracking methods. Steady RANS does not capture the wake structures accurately and this affects the contamination prediction. URANS is able to recover the large-scale wake unsteadiness seen in the experimental data, but the difference between the experimental and computational contamination distributions is still notable. The CFD is also able to provide further insight by showing the behaviour of particles of different sizes. Large particles are found to take on a ballistic trajectory and penetrate the wake. In contrast, small particles are shown to be less likely to become entrained into the wake.

\section{Introduction}

Contamination of vehicle rear surfaces is a significant issue. It can degrade the performance of lighting, obstruct visibility through the rear window and lead to glass degradation due to abrasion and premature wear of wiper blades [1]. Contamination can also influence the performance of rear camera systems by obstructing camera lenses [2]. Furthermore, it can be a source of dissatisfaction in instances when dirt gets transferred onto the user upon contact with the vehicle exterior.

In general, there are three sources of vehicle surface contamination. The first two sources are wind-driven rain (referred to as primary contamination) and a mixture of water and solids raised by vehicles from the road surface which are consequently deposited on the surface of preceding cars (also referred to as third-party contamination). Finally, the third source is called self-soiling and results from the spray generated by the rotation of the vehicle's wheels without any influence from other road users. The contaminant spray is advected into the vehicle's wake which deposits it onto the rear surfaces. These processes involve a complex and broad range of multiphase physics. The issue of self-soiling is particularly relevant for vehicles with a large base area, such as off-road vehicles, Sports Utility Vehicles (SUVs) and Estates (Station wagons). This is because the blunt rear geometry of these vehicles causes the formation of strong large-scale recirculating vortices which draw spray towards the rear surfaces [ $\underline{3}]$.

To date, the most successful counter measures against contamination have been systems that redirect water and air away from the critical areas on the vehicle surface. For example, spray suppression has been achieved for heavy goods vehicles by the use of textured flaps, combined with either fenders or valances [4]. However, such design solutions have historically focused on reducing spray hazard to other road users, rather than reducing deposition on vehicle surfaces. 
Interestingly, more recent work has shown that overall aerodynamic improvements to the vehicle design which reduce drag can also reduce spray ([] $]$, []]). This raises the prospect of controlling surface contamination through improvement in vehicle geometry. This can only be done if contamination control is integrated as a design consideration as early as possible in the design process, when the fundamental vehicle geometry is being developed [ $\underline{3}]$. Even very small changes in the design of vehicle parts, such as wheel arches and the under-body, can significantly influence levels of contamination [1] because the strength and location of the important flow structures differ for each design. Rectifying problems after the first prototype has been developed can be very costly. This work is thus motivated by the desire to develop techniques that will allow the level of contamination to be estimated for a vehicle before any representative physical model is made.

In order to predict surface contamination, experiments and computational fluid dynamics (CFD) codes are increasingly used. It is important that any CFD method used for contamination prediction is validated against suitable experimental data. Experiment and CFD together can also provide physical insight into the mechanisms which transfer water and dirt onto the exterior surface of the vehicle.

This study focuses on rear surface contamination of a Windsor model (also called the Rover model, see [7]) using wind tunnel testing and CFD with the experimental results being used for validation of the CFD simulations. The CFD approach employed uses RANS and URANS to predict the flow field, together with Lagrangian particle tracking for the contamination phase and compares the surface contamination patterns to the experimentally obtained results. This work is an attempt to consider surface contamination mechanisms in controlled wind-tunnel conditions with a generic, representative, vehicle body that reduces the number of unknowns in the test case and increases the generality of any conclusions drawn. The work reported contains three main elements:

- An initial validation exercise the flow-field in the wake predicted by RANS and URANS is compared with the experimental data obtained in a separate study of the same geometry.

- Rear contamination patterns are visualised by the use of a water spray containing a UV dye injected underneath the rear of the vehicle. The effect of changing spray conditions is investigated experimentally by repeating the test using different spray nozzle pressures.

- A single spray condition is then simulated with Lagrangian particle tracking.

The work reported is the first introductory stage of a larger research project.

\section{Previous Relevant Work}

Concerns over vehicle contamination gained increasing attention in the 1960s. Before then, the impact of deposition of liquid on vehicle surfaces had only been considered in the aeronautical industry, for example by Rhode [ㅁ]. In 1965, Dawley [9] pointed out that the flow of air across the roof of a station wagon vehicle separates from the rear edge of the roof and forms a wake behind the vehicle. He contended that this wake raises mud and dust from the road and deposits it onto the back window. He proposed installing deflecting vanes at the rear corners of the body to provide clean air into the wake.

Maycock [10] studied surface contamination of road vehicles and suggested that spray-laden air is drawn into the region immediately behind bluff vehicles, which is why their rear surfaces become rapidly soiled. In addition, Weir [11] looked into the aerodynamic effects of large trucks, noting that due to their boxy shape, there is always a typical subsonic base separation region. Further insight into the flow mechanisms associated with rear surface contamination was provided by Costelli [12] in a technical paper on the development of the Fiat UNO car. The issue of contamination on the rear window had been addressed in the development process; the author noting that the problem of rear window contamination is brought about by the pressure variation in the near-wake and that droplets tend to be deposited in regions of relatively high base pressure.

One of the earliest published CFD studies that looked into side and rear contamination of an SUV was done by Yoshida et al. [13]. The geometry used was greatly simplified due to the limited computing capabilities of that time. They used a "Dirt particle path" (Lagrangian), as well as "Dirt concentration" (Eulerian) methods.

One of the conclusions was that a steady-state flow field gives the same contamination result as when using an unsteady flow field although several subsequent works (see [14] and [15], for instance) have found contrary results. The difference between the timeaveraged and transient computations was studied by Roettger et al. [14]. They found that by using a time averaged flow field to predict the path of a particle reduces the probability of that particle hitting the vehicle compared to using a time varying field. Paschkewitz in [15] emphasizes that bluff body wakes are extremely complex as they are highly unsteady and separated. This leads to simulation of particle-wake interactions being very challenging because small differences in the flow field can lead to large differences in the particle dispersion behaviour.

A study on vehicle soiling has been also presented by Kuthada and Cyr [16]. Apart from CFD computations, this study involved full scale tests to study splash and spray of water from a free rotating wheel. The computational results of vehicle side contamination also matched the experimental data to a good extent. One of the conclusions was that although simple computational models can be used to study vehicle soiling, some advanced prediction methods, such as modelling of particle break-up, are needed.

More recent, mainly computational work on surface contamination prediction has been reported by Gaylard and Duncan [ $\underline{3}]$, as well as Gaylard et al. ([2] and [1] ). Among their findings is that the aerodynamic field influences the advection of small droplets into the wake behind vehicles and that the water sprays ejected by rotating wheels force droplets to penetrate into the wake region. The experimental work presented in [ $\underline{3}]$ involved both wind tunnel and track testing. In the more controlled wind tunnel environment, the 
largest concentration of spray was on the rear glass and the centre of the lower tailgate door. In addition, this study used CFD to compute the body side contamination and rear surface contamination. It considered water sprays ejected from a rotating wheel, as well as the dripping and splashing of particles from the wheel house and the rear under body. Lagrangian particle tracking was used as a postprocessing step for a number of 'frozen' transient data frames. The computational results were consistent with experimental data.

In contrast, work described in [2] used a fully unsteady particle tracking approach. The fully unsteady approach provided improved results for rear surface contamination. The results also showed that the splash model is more important for predicting side body contamination, rather than rear surface contamination. This study also looked into the effect of wheel and vehicle wake. The authors emphasize that both these wakes result in a significant contribution to rear and side contamination of the vehicle. In addition, this study looked into the effect of the moving ground boundary condition. It was noted that the introduction of a moving floor modifies the vehicle wake by reducing its length. As a result, more particles are able to maintain their momentum and reach the rear surface of the vehicle. The authors also emphasize that the moving ground boundary condition introduces additional unsteadiness to the vehicle wake which leads to increased mixing and hence more particles entering into the recirculation. The more recent of the studies [1] considered interactions between the particles and the flow field (two-way coupling); the two-way coupled simulation produced better agreement with experiment. This was noticeable in the general shape of the contamination pattern over the rear surface, and particularly in the license plate region. In addition, it demonstrated that the rear tyres are the dominant source of rear surface contamination.

These previous studies highlight the many complex physical processes that form part of the contamination process and give some idea of the number of aspects of physical modelling that are required before reliable on road contamination patterns can be predicted. It is very difficult to isolate, and therefore judge the importance of any of these individual sub-models when there are unknown parameters. For example, if the size distribution of the spray thrown up by the wheels is unknown then it is very difficult to judge how accurate the modelling of the spray transport is. It is therefore desirable to eliminate as many unknowns as possible when developing validation cases for surface contamination modelling, for example by using a spray nozzle with a known distribution. Furthermore, much of the previous work has been carried out by automotive manufacturers who have understandably concentrated on specific vehicles. However a great deal of value has been gained in the field of vehicle aerodynamics by looking at simplified or generic vehicle bodies. While lacking the details and styling of specific vehicles these generic bodies allow the study of relevant flow features in well characterised and repeatable settings. (For example, [7] provides an extensive overview of the simple bodies and basic car shapes used in automotive aerodynamics.) This work represents an attempt to apply this same practice of using a standard generic test case to vehicle contamination studies.

\section{Experimental Method}

\section{Physical Model}

The physical model used in the study is the Windsor Body shown in Figure 1. The details of this model have been well documented previously (see, for example [7], [17] and [18]). The model is $1.044 \mathrm{~m}$ long, $0.389 \mathrm{~m}$ wide and $0.289 \mathrm{~m}$ high. Most of the leading edges are well rounded to avoid separation. The advantage of this model is that it is simple in shape, but at the same time represents approximately a quarter-scale small car. This model was designed to generate specific wake features associated with rear geometry parameters such as slant angle and is therefore a good platform with which to study how rear wake structures influence contamination. According to a previous study conducted by Passmore and Littlewood [19], the model is insensitive to Reynolds number above 1.4 million. During contamination experiments, the model was mounted to a 6 -component balance via thin pins of $0.008 \mathrm{~m}$ in diameter. The balance measurements were not recorded as only the contamination pattern was of interest. The ground clearance was set to $0.05 \mathrm{~m}$. The distance between the pins was $0.680 \mathrm{~m}$, placed symmetrically.

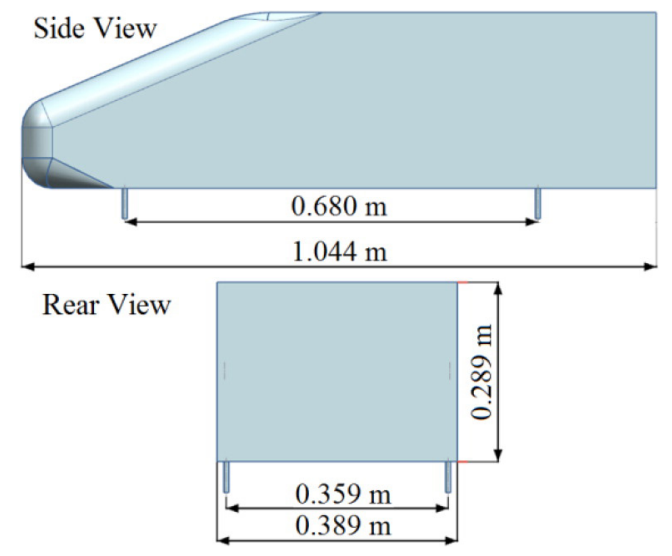

Figure 1. Windsor model CAD.

\section{Wind Tunnel Configuration}

The Wind Tunnel at Loughborough University has an open loop, closed working section configuration. The working section is $1.92 \mathrm{~m}$ wide, $1.32 \mathrm{~m}$ high and $3.6 \mathrm{~m}$ long and fits models scaled up to $25 \%$, producing a blockage of $5 \%$. The $140 \mathrm{~kW}$ fan produces a maximum working section freestream velocity of $45 \mathrm{~m} / \mathrm{s}$. During contamination tests, data was obtained at freestream speeds of $15 \mathrm{~m} / \mathrm{s}, 30.5 \mathrm{~m} / \mathrm{s}$ and $40 \mathrm{~m} / \mathrm{s}$. This paper focuses on contamination data recorded for the most extensive data set, collected at a freestream speed of $30.5 \mathrm{~m} / \mathrm{s}$. The aerodynamics tests, on the other hand, had been performed prior to the contamination tests at a single freestream velocity of $40 \mathrm{~m} / \mathrm{s}$. The boundary layer displacement thickness (with no model present) at airspeed of $40 \mathrm{~m} / \mathrm{s}$ at the centre of the balance is $0.007 \mathrm{~m}$ and the freestream turbulence intensity is $0.2 \%$. The pressure data was corrected for blockage using the continuity correction, Equation 1. In the equation, $T A$ and $M A$ correspond to the wind tunnel cross section area and the model frontal area, respectively. $C_{P}$ and $C_{P_{\text {corr }}}$ are the 
recorded surface pressure coefficient and the corrected surface pressure coefficient, respectively. This pressure correction procedure is also applied to CFD results.

$$
C_{P_{\text {corr }}}=1-\left(\frac{1-C_{P}}{\left(1-\frac{M A}{T A}\right)^{2}}\right)
$$

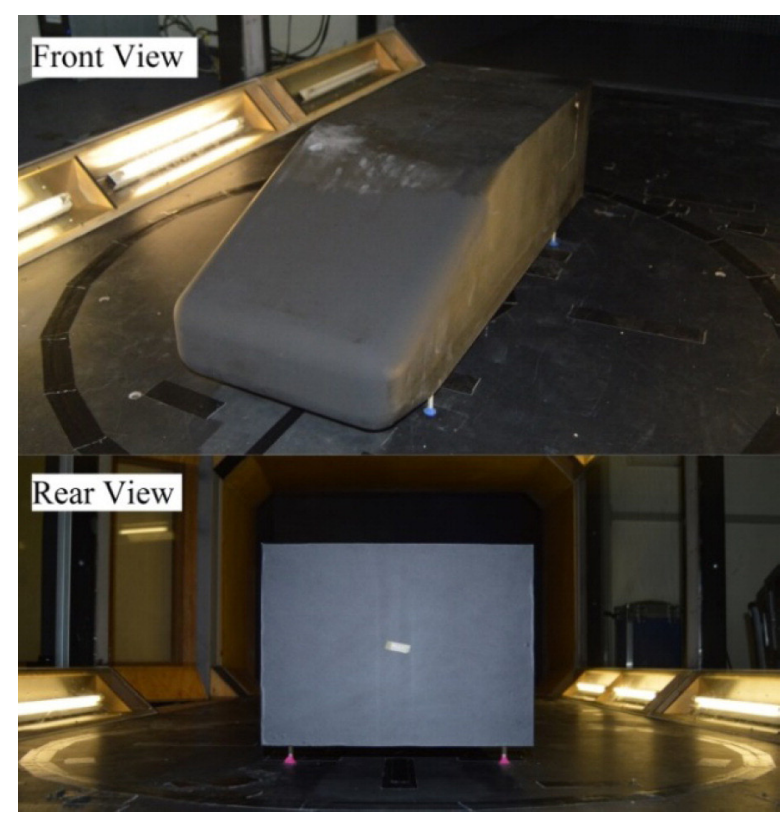

Figure 2. Windsor Body in the Loughborough Wind Tunnel.

\section{Aerodynamic Tests}

The aerodynamic data presented in Figures 3 and $\underline{4}$ was collected as part of a separate study so the setup and experimental details are not covered in great depth here. The data includes the pressure distribution on the base of the model and instantaneous flow field data in the $y$-x plane immediately behind the model, both sets of data collected at $40 \mathrm{~m} / \mathrm{s}$. The pressure data are covered in some depth by Pavia et al. [마] and the instantaneous flow field data will be the subject of a future publication.

Figure 3 presents the time averaged pressure distribution on the base of the Windsor model. Data were captured at a frequency of $260 \mathrm{~Hz}$ and averaged over $315 \mathrm{~s}$. The numbered points in Figure 3 correspond to the location of pressure taps. The distribution of pressure suggests the dominance of large-scale lateral unsteadiness, which can be further understood by considering Figure 4 . Pavia suggests that the asymmetry in the pressure distribution shown in Figure 3 is due to the insufficient number of pressure taps, and due to the lack of taps on the vertical centreline, in particular [미]

A total of 1000 instantaneous images were collected at a sampling rate of approximately $7.26 \mathrm{~Hz}$. The results presented in Figure 4 show a single instantaneous velocity field reconstructed from the first 50 modes of a POD analysis. This technique helps capture the most energetic modes and removes noise. The theory behind the POD technique can be found in [21],$[\underline{22}]$ and [23] . The advantage of using POD in this work is that it reveals the presence of a lateral wake biinstability which would not be seen if the averaged or instantaneous fields (too noisy) were used instead. Figure 4, horizontal mid-plane, illustrates the two modes of a horizontal bilateral instability, in which there is a sequential dominance of each vortex. This can be thought of as a large scale (both in time and in size) flapping of the wake and has been also observed by Al-Garni et al. [24] on the flow around a generic SUV. High wake unsteadiness results in the flow alternately separating off each side and impinging close to the opposite edge which results in the pressure distribution seen previously in Figure 3. The timescale of the bilateral instability is of order 10 to 30 seconds, and therefore explains the difficulty in producing a symmetrical mean field illustrated by the asymmetric base pressure distribution shown in Figure 3.

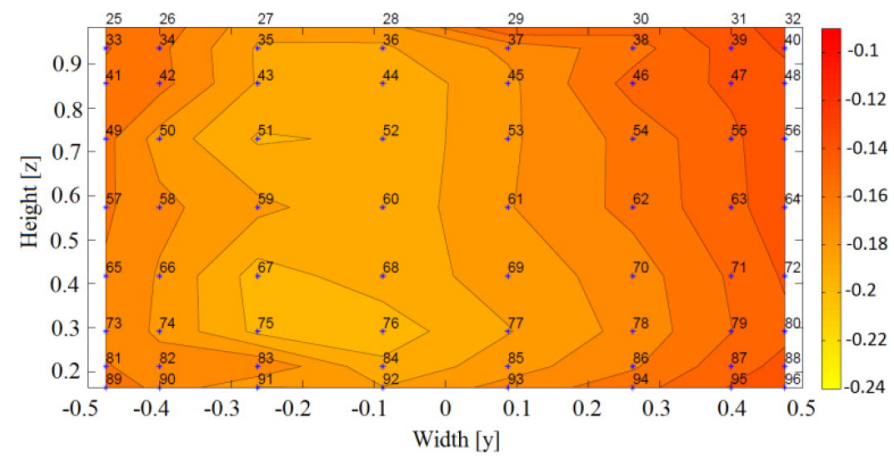

Figure 3. Pressure distribution on the base of the Windsor Body.

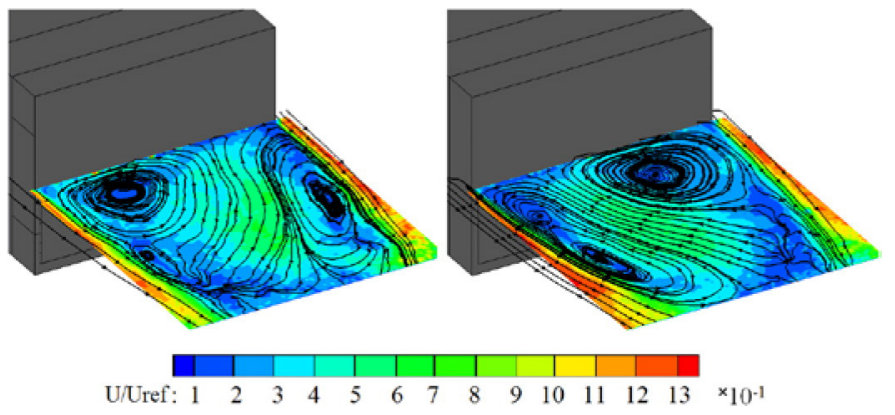

Figure 4. Instantaneous flow field in $\mathrm{y}$-x mid plane, post processed using POD.

\section{Contamination Tests}

\section{Seeding Setup and Spray Characteristics}

In order to provide an understanding of the role of droplet size in the transport of contaminant onto the vehicle, and produce well defined conditions for CFD validation, it is desirable that a known spray droplet size distribution can be provided. Ideally, this needs to be measured in the experiments. In this work, however, we used a commercial pressure atomising nozzle whose spray characteristics were available from the manufacturer.

The typical droplet mean diameter (assuming droplets are spherical) in road conditions for a full scale car ranges from 80 to $300 \mu \mathrm{m}$ [25] While it is not possible to keep all non-dimensional parameters the same we have chosen to scale using Stokes number as this will ensure that droplet advection processes are representative of real world geometries. This gives a required droplet mean spherical diameter (subsequently referred to as the droplet size) of $20-75 \mu \mathrm{m}$ for a quarter scale model. The nozzle used in the experiments is BETE MW105. Full specification of the nozzle can be found in [26]. The droplet size distribution produced by the nozzle is dependent on pump pressure. In the experiments, three sets of data were obtained by running the 
pump at $1 \mathrm{MPa}, 4.5 \mathrm{MPa}$ and $11 \mathrm{MPa}$. These pressures were calculated to produce the droplet distribution seen in Figure 6, with peak droplet sizes of $19.6 \mu \mathrm{m}, 25.6 \mu \mathrm{m}$ and $40.2 \mu \mathrm{m}$, respectively.

The seeding setup can be seen in Figure 5. A single nozzle, installed in the mid-plane and directed 45 degrees downstream was used. It was placed underneath the rear part of the model, in line with the back surface. We have deliberately chosen to position the nozzle centrally and use a model with no wheels to eliminate the effect of wheel wakes on the contamination mechanism. Future work will look at including the effect of such mechanisms and having a datum case with no such mechanism will provide a useful comparison. However, it is realized that the wheels are the main source of rear soiling and particles are not generally emitted directly into the wake in road conditions. Nevertheless, the main focus of this study was to use a simplified case to assess the ability of RANS and URANS to match experimental results, rather than perform very realistic experiments.

A mixture of UV dye (Tinopal SFP powder at $1 \mathrm{~g} /$ litre) and water was used as the contaminant. A UV lamp with matched wavelength illuminated the model and allowed the contamination pattern to be seen. Although the geometric angle of the nozzle is constant throughout the experiment, the spray cone angle $\varepsilon$ seen in Figure 5 varies with the pump pressure.
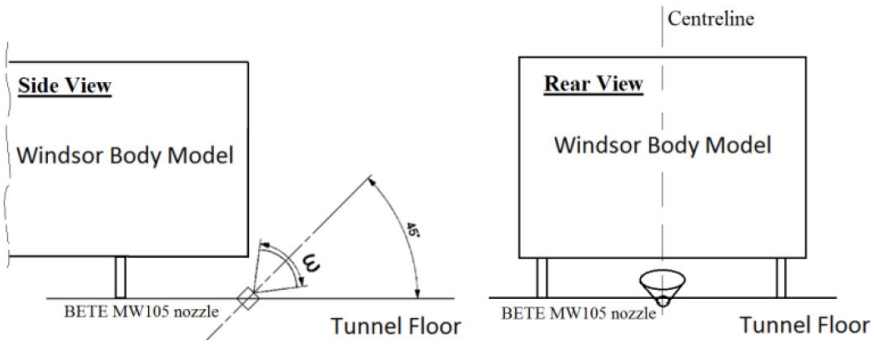

Figure 5. Seeding Setup.

The flow rate is estimated using Equation 2, in which the $\mathrm{k}$ factor is an empirical value provided by the manufacturer. The pressures and the peak droplet sizes can be seen in Table 1, along with the flow rates produced at these pressures. While the exact droplet speeds at given pressures are unknown, they can be estimated using the nozzle diameter and flow rate. Hence with a nozzle pressure of $11 \mathrm{MPa}$ relatively small droplets with high injection speeds result whereas for the $1 \mathrm{MPa}$ case larger droplets with lower injection speeds will be found. In general increasing the nozzle pressure will increase the momentum of the spray.

$$
Q\left(\frac{l}{\min }\right)=k \sqrt{P(\text { bar })}
$$

Table 1. Estimated droplet sizes and flow rates at chosen pressures

\begin{tabular}{|l|l|l|}
\hline Pressure [MPa] & Peak Droplet Diameter $[\boldsymbol{\mu m}]$ & Flow Rate $[\mathbf{[} / \mathbf{m i n}]$ \\
\hline 1 & 40.0 & 0.0478 \\
\hline 4.5 & 25.6 & 0.1026 \\
\hline 11 & 19.6 & 0.1574 \\
\hline
\end{tabular}

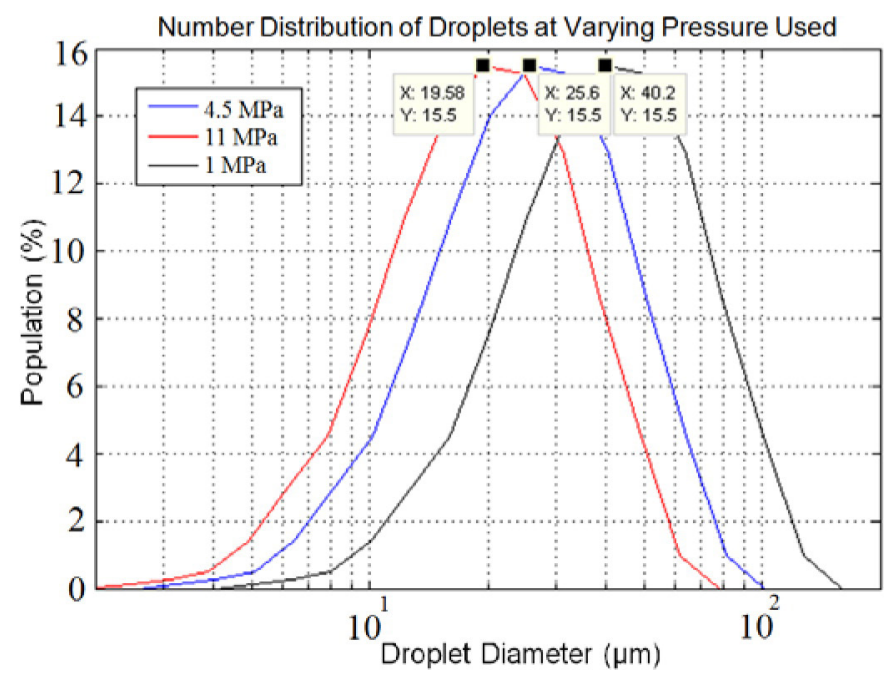

Figure 6. Droplet distribution produced by BETE MW105.

\section{Data Collection Techniques}

The most common process of data collection from experimental soiling investigations is based on image processing (see [1] , for example). The fluorescence produced by the doped liquid used in experiments is related to pixel values, which are larger for thick films and can be processed to produce soiling intensity plots. Soiling intensity is a function of the liquid depth and is used here to provide qualitative indication of the distribution of contaminant over the surface. In this study, images of the soiled rear surface, illuminated by a UV lamp, were taken with a digital SLR camera.

Unfortunately, it was not feasible to keep the camera inside the wind tunnel during tests. Therefore, the camera was brought inside the test section after each test to record the data. Great care was taken to set up the camera in the same position for each image to ensure consistency. The UV lamp was positioned outside the wind tunnel as shown in Figure 7. In future tests, the UV lamp will be positioned normal to the surface to ensure uniform illumination. A thin semitransparent sheet of polyethylene was used to diffuse the light and decrease light intensity. The camera settings used were an exposure time of 15 seconds and an ISO value of 100 (the lowest available on the camera). The location of the equipment during data collection is illustrated in Figure 7.

UV Lamp

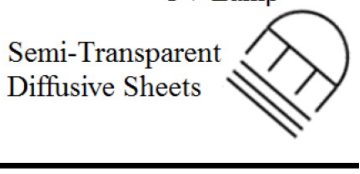

Test Section

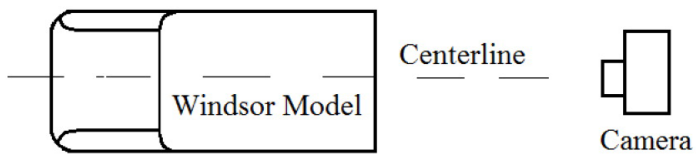

Figure 7. Camera and lamp location. 


\section{Computational Set-up}

\section{Computational Grid and Boundary Conditions}

Computational simulations were performed using an open source CFD software (OpenFOAM $®)$ [27]. A three-dimensional mesh was generated around the Windsor Body model using snappyHexMesh, a meshing algorithm available within this software suite (see Figure 8). The domain height was set corresponding to the height of the test section in the wind tunnel $(1.32 \mathrm{~m})$. The inlet was placed $5.7 \mathrm{~L}$ ahead of the model, where $\mathrm{L}$ is the length of the model. The inlet velocities matching both the aerodynamics experiments $(40 \mathrm{~m} / \mathrm{s})$ and contamination measurements $(30.5 \mathrm{~m} / \mathrm{s})$ were used; the latter giving a length-based Reynolds number, $\operatorname{Re}_{\mathrm{L}}=2.03 \times 10^{6}(\mathrm{~L}=1.044 \mathrm{~m})$. The boundary layer on the walls was allowed to grow from $3.5 \mathrm{~L}$ ahead of the model, by applying a no-slip condition from this point. This length was calculated to be sufficient for the boundary layer to reach an approximately same thickness as had been recorded in the experiments. The outlet was placed $6 \mathrm{~L}$ downstream of the model. The same computational procedure was used in [28] , in which a good agreement with an experiment was obtained in the same wind tunnel arrangement. Refinement regions and prism layers were added around the model and in the rear portion of the car to capture strong gradients in the flow (including separated flow regions). The minimum cell size was $3 \mathrm{~mm}$ and it was not small enough to refine the mounting pins. As a result, the pins were neglected as they were also believed to have minimal influence in RANS and URANS computations. Wall functions were used and the first prism cell around the model was placed in the logarithmic region of the boundary layer $\left(\mathrm{y}^{+} \approx 30\right)$.

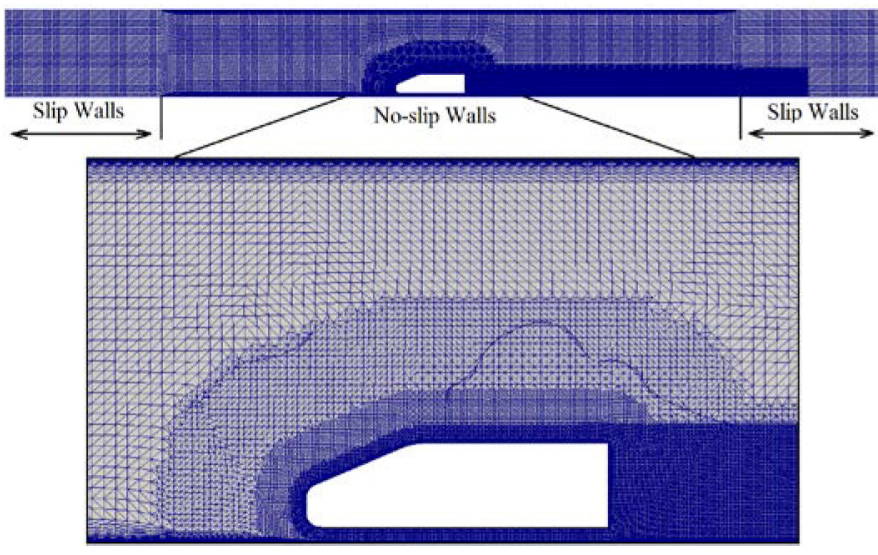

Figure 8. Grid produced with SnappyHexMesh.

\section{Turbulence Modelling}

Employment of Reynolds-averaged Navier-Stokes (RANS) equations is still the most common approach to turbulence modelling and its cost advantages over eddy-resolving methods means that it is attractive if its accuracy is found to be sufficient. For example, RANS approaches require shorter simulation times and simplified postprocessing. However, many engineering flows are inherently unsteady and this can be addressed in a limited sense using unsteady RANS (URANS). Although the duration of unsteady simulations depends on the physical time computed and the grid refinement used, URANS is considered to be one of the least computationally expensive methods to predict the behaviour of unsteady flows. On the other hand, while URANS is able to capture some large scale unsteadiness, it is generally unable to reproduce organized structures found in shear layer mixing, which may play an important role in particle dispersion [29].

In the study, two different sets of data are obtained, one employing RANS and the second using the URANS turbulence solvers. Both sets use the realizable $k-\varepsilon$ turbulence model to close the equations. This contains modifications to the standard $k-\varepsilon$ model which ensure that the turbulence field predicted by the model remains physically realizable. It is known to perform well in problems involving steep pressure gradients (see, for example, [이]). The inlet values for $k$ and $\varepsilon$ are derived from the freestream velocity and a turbulent intensity of $1 \%$. A higher value is used at inlet than reported in the experiment as this will decay in the simulation before the flow reaches the model, the higher value also adds some extra numerical stability to the RANS solution. The Navier-Stokes equations are solved using the incompressible PIMPLE (merged PISO-SIMPLE) pressure-correction algorithm. The time step used for the URANS simulations is $1.25 \times 10^{-5} \mathrm{~s}$, ensuring the CFL number remains below 1 .

\section{Particle Tracking}

The current study uses the Lagrangian model to simulate droplet spray in the domain. In the Lagrangian description, the spray is represented by points, or particles. This approach uses Navier-Stokes equations to solve the continuous phase (air), while equations of motion are used to predict the dynamics of particles. The translational motion of particles is governed by Newton's second law, shown in Equation 3 , where $\mathrm{m}_{\mathrm{p}}, \mathrm{u}_{\mathrm{p}}$ and $\mathrm{F}$ are the particle mass, particle velocity and the force acting on the particle, respectively.

$$
m_{p} \frac{d \boldsymbol{u}_{p}}{d t}=\boldsymbol{F}
$$

This equation is integrated twice with respect to time to update the position of the particle. The most general form of $\mathrm{F}$ is referred to as the Basset-Boussinesq-Oseen (BBO) equation, which considers the added mass, Basset, Magnus, Saffman, pressure, buoyancy, drag and gravitational forces. According to [1ㅣ] and [32], only drag and gravitational forces are of major importance. As a result, this study neglected all forces, except for the drag and gravity of particles. The simplified computed force on each particle is thus as shown in Equation 4.

$$
\boldsymbol{F}=-\frac{\pi D^{2}}{8} \rho C_{D}\left|\boldsymbol{u}_{p}-\boldsymbol{u}\right|\left(\boldsymbol{u}_{p}-\boldsymbol{u}\right)+m_{p} \boldsymbol{g}
$$

In this equation $\mathbf{u}$ is the local air velocity; the drag coefficient $\left(\mathrm{C}_{\mathrm{D}}\right)$ is found as a function of particle slip Reynolds number by the widely used Schiller Naumann correlation for small spheres [33]. The particles will be redistributed by the turbulent motion of the air as well as the mean velocity. Hence some method of accounting for the unresolved turbulent structures must be employed in RANS modelling. Here a stochastic dispersion model is employed which follows Gosman and Ioannides [34]. This adds a stochastic component $\mathbf{u}^{\prime}$ to the gas velocity seen by each parcel, where a different $\mathbf{u}^{\prime}$ is chosen for each parcel from a Gaussian random number distribution with standard deviation equal to $\sqrt{ } 2 k / 3$. A new value of $\mathbf{u}^{\prime}$ is chosen for a parcel after a time equal to the local 
turbulent timescale given by $k / \varepsilon$. The effect of this turbulent fluctuation on a parcel will therefore depend on the local turbulence as well as the particles' size, with smaller particles responding more.

In the URANS computations, particle tracking is simulated using a concurrent approach, where the dynamics of particles are calculated within the solver at each time step. To account for unresolved turbulent motion in the URANS formulation the stochastic dispersion model is retained. The effect of particles on the surrounding fluid is not taken into account, i.e. a one-way coupled approach is used here. Hence, the gas phase is considered to be unaffected by the presence of particles and particle-particle interactions are neglected. The importance of particle-flow interaction can be estimated using a momentum coupling parameter, Equation 5. This parameter represents the ratio of particle drag to the carrier fluid momentum flux [35]. In the equation, term $C$ corresponds to the ratio of the mass flow rates of the dispersed and continuous phases. The Stokes number $S t$ quantifies the relative importance of particle inertia and is given in Equation 6. According to [프] , the back-coupling may be important if the momentum coupling parameter is greater than unity. Assuming an airflow of $30.5 \mathrm{~m} / \mathrm{s}$ and a $0.0195 \mathrm{~m}^{2}$ area underneath the model (a $0.39 \mathrm{~m} \times 0.05 \mathrm{~m}$ passage), the mass flow rate is approximately 0.7 $\mathrm{kg} / \mathrm{s}$. The amount of water injected at $4.5 \mathrm{MPa}$ is $0.00171 \mathrm{~kg} / \mathrm{s}$, giving a mass loading ratio of $2.4 \times 10^{-3}$. For the peak droplet size of $25.6 \mu \mathrm{m}$ the Stokes number is 0.4 , which results in $\Pi=1.7 \times 10^{-3}$. This suggests that the effect of particles on the surrounding fluid can be neglected, as $\Pi<<1$.

$$
\Pi \approx \frac{C}{1+S t}
$$

\section{Spray Model}

The spray is modelled by injecting particles using a cone injector with a cone angle of 70 degrees, positioned and oriented as in the experiments. Only the $4.5 \mathrm{MPa}$ case is simulated in this work since the qualitative data is similar for all test cases as shown in the following section. The injection speed of the particles was estimated to be $15.2 \mathrm{~m} / \mathrm{s}$, based on the mass flow rate of $0.00171 \mathrm{~kg} / \mathrm{s}$ and the nozzle diameter of $0.378 \mathrm{~mm}$. The particle size (Figure 6) shows a range of droplet sizes for the $4.5 \mathrm{MPa}$ injection pressure, so four different CFD cases were computed to see how particles of various sizes behave in the wake (Table 2). The injection speed was held constant for each case.

The Stokes number of particles was calculated using Equation 6 , based on the half of the height of the model. In the equation, $\rho_{d^{\prime}} d_{d}$ and $U_{\infty}$ are the density of the particles $\left(1000 \mathrm{~kg} / \mathrm{m}^{3}\right)$, the diameter of the particles and the freestream velocity, respectively. The characteristic dimension of an obstacle is denoted with $l$ (half of the model height) and the dynamic viscosity of the gas is $\mu_{\mathrm{g}}$.

$$
\text { St }=\frac{\rho_{\mathrm{d}} \mathrm{d}_{\mathrm{d}}^{2} \mathrm{U}_{\infty}}{18 \mu_{\mathrm{g}} l}
$$

The likelihood of particle break-up was estimated based on the Weber number. The Weber number is defined as the ratio of inertia forces to the surface tension of a given particle and can be estimated using Equation 7. In the equation, $U_{s l i p}, \rho_{f}$ and $\sigma_{p}$ are the slip velocity, the density of the fluid and the surface tension of the liquid (water), respectively. The worst case scenario was considered with $U_{\text {slip }}$ equal to the freestream velocity. The consideration of a break-up becomes important when the Weber number exceeds 10 [16]. Table 2 shows that none of the particles reach the critical Weber number. As a result, the break-up of particles was not considered.

$$
\mathrm{We}=\frac{\rho_{\mathrm{f}} \mathrm{U}_{\mathrm{slip}}^{2} \mathrm{~d}_{\mathrm{d}}}{\sigma_{\mathrm{p}}}
$$

Table 2. Numerical cases

\begin{tabular}{|l|l|l|l|l|}
\hline Case & $\begin{array}{l}\text { Droplet size } \\
{[\mu \mathrm{m}]}\end{array}$ & Stokes number & Weber number & $\begin{array}{l}\text { Fraction that the } \\
\text { droplets take up in the } \\
\text { distribution }\end{array}$ \\
\hline 1 & 102 & 6.57 & 1.56 & $<0.5 \%$ \\
\hline 2 & 25.6 & 0.4 & 0.39 & $15.6 \%$ (Peak) \\
\hline 3 & 4 & 0.01 & 0.06 & $<0.5 \%$ \\
\hline 4 & $\begin{array}{l}\text { Full } \\
\text { Distribution }\end{array}$ & $0.01 \leq \mathrm{St} \leq 6.57$ & $0.06 \leq \mathrm{Wb} \leq 1.56$ & $100 \%$ \\
\hline
\end{tabular}

The nozzle used in the experiments injects a very large number of droplets over a very short period of time. Hence, simulating each injected droplet with an individual particle is too computationally expensive. As a result, most numerical tools that use the Lagrangian particle tracking approach simplify simulations by tracking groups of particles (parcels). Increasing the number of parcel streams improves accuracy by creating a larger ensemble of tracks, each track representing a different realization of the particle trajectory. On the other hand, increasing the number of parcels increases the computational cost. In this work we inject the same mass of particles in each simulation $(0.00171 \mathrm{~kg} / \mathrm{s})$ split between a maximum of $1 \times 10^{7}$ parcels per second. For the constant size tests all parcels represent particles of the same size (note that for the $102 \mu \mathrm{m}$ diameter particles, less than $1 \times 10^{7}$ particles are injected per second ensuring that an equal number of parcels are used, each representing an individual particle). For the polydisperse distribution case parcels are released representing a number of particles of a given diameter drawn from the size distribution.

\section{Results}

\section{Experimental}

Figure 9 presents base contamination data for three different spray nozzle pressures collected at 15, 30 and 60 seconds from the start of the test. In the figure, soiling intensity data is shown that ranges from 0 to 1 , corresponding to no contamination and maximum contamination, respectively. The freestream air velocity for all three cases was $30.5 \mathrm{~m} / \mathrm{s}$. 


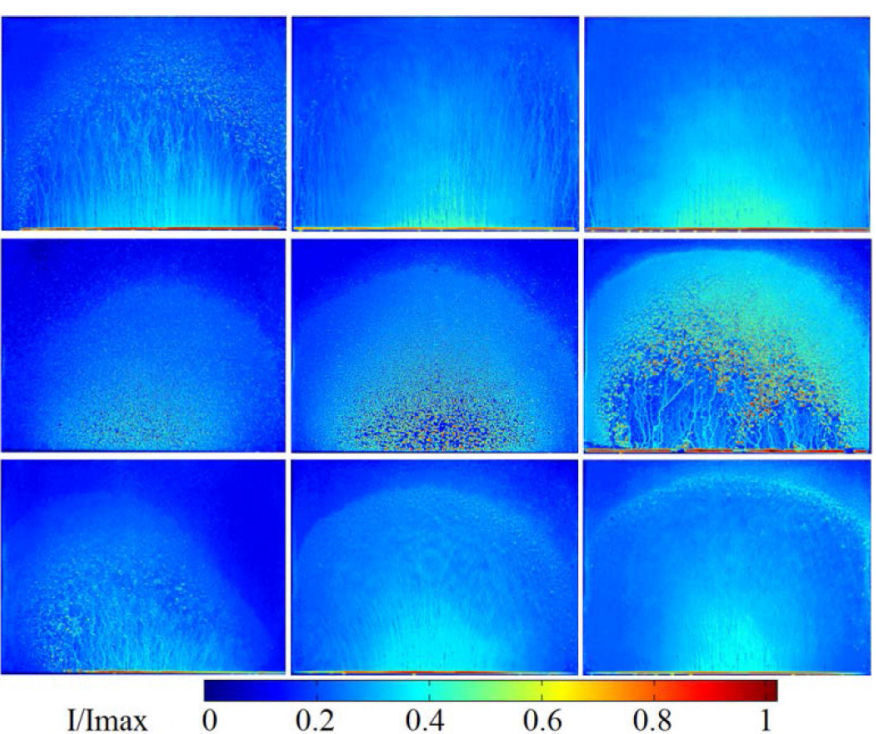

Figure 9. From left to right: base contamination at $15 \mathrm{~s}, 30$ s and $60 \mathrm{~s}$. From top to bottom: $11 \mathrm{MPa}$ test case (top), $4.5 \mathrm{MPa}$ test case (middle), $1 \mathrm{MPa}$ test case (bottom).

It can be seen that for the 11MPa case the whole area of the base gets covered with some water as early as 15 seconds into the test. This relatively even spread is maintained at 30 and 60 seconds, although higher contamination intensity is seen at the centre of the lower part of the base. This more even spread may be due to a higher droplet seeding speed, in combination with a reduced mean droplet diameter. As a result, droplets penetrate further into the wake, while at the same time their smaller size allows them to be spread more evenly in the wake. Due to their smaller mean size their trajectories are dominated by aerodynamic forces, with gravitational force less of an influence. As a result, they cover almost the whole area of the model base shortly after they have been injected.

There is some evidence of streaking (rivulet formation) due to droplets running down the rear of the base at $15 \mathrm{~s}$, which becomes progressively less pronounced. The early-time streaking may be an artefact of the test. It was noted that the pump takes a few seconds to reach working pressure, during which time larger than intended droplets will be introduced into the experiment. Similarly, when the pump is switched off the line pressure has to bleed out through the nozzle as there is a no pressure release. This allows droplets of increasingly large size to be seeded into the flow field whilst the tunnel speed is decreased. These effects will cause the largest discrepancy for the highest test pressure.

For the $4.5 \mathrm{MPa}$ injection case the concentration of the contaminant at the centre of the lower part of the base is seen more clearly. At 30 and 60 seconds the spray is seen to form larger droplets and rivulets in this region due to coalescence of water once it has been deposited on the surface. These larger droplets and rivulets show up in Figure 9 as the red patches showing large amounts of UV dye present at that point. This behaviour is not present in the $1 \mathrm{MPa}$ results, for which larger droplets of lower injection velocity will be expected. This suggested that less water is collecting on the lower part of the base compared to the $4.5 \mathrm{MPa}$ case. The $1 \mathrm{MPa}$ results also show the most concentrated water intensity at the bottom centre of the base of all the three cases.
For all three cases, results show that the contamination pattern begins at the centre of the model at the lower edge, and as the seed time increases this pattern moves outwards in an arc from the centre of the lower edge. This is seen most strongly for $4.5 \mathrm{MPa}$.

Some of the contamination images taken during experiments exhibited varying amounts of asymmetry about the vertical mid plane. The effect of this on contamination is seen in Figure 10 where for two $4.5 \mathrm{MPa}$ tests an asymmetry is seen in the contamination pattern. Figure 11 shows two snap shots from a video taken during experiments that shows the dominance changing from one side to another of the lower corner vortices. The time that these vortices can remain stable for is in the region of 40 seconds which is longer than some tests. This is the effect of the bilateral wake instability shown in Figure 4.
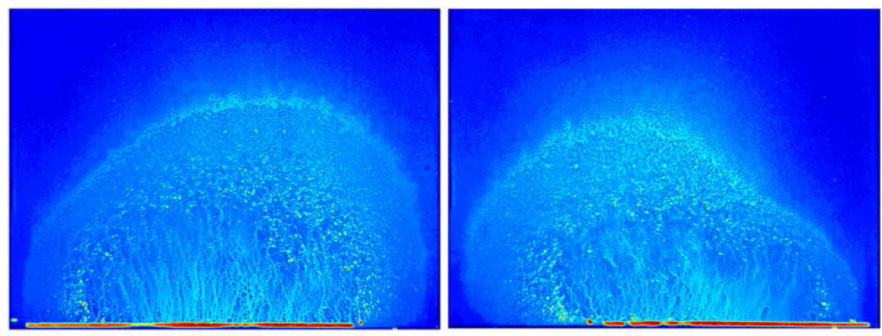

Figure 10. Right and left offset recorded at $\mathrm{U}_{\infty}=40 \mathrm{~m} / \mathrm{s}, \mathrm{P}=4.5 \mathrm{MPa}$.
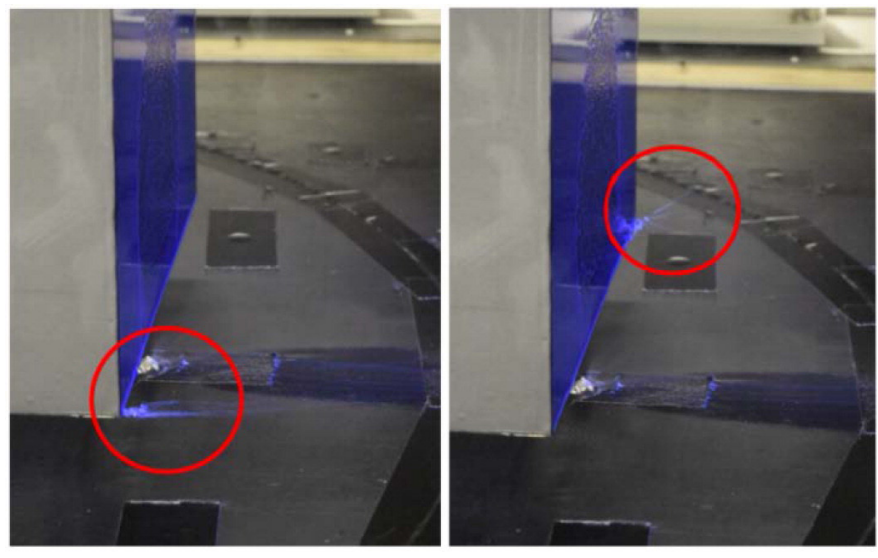

Figure 11. Video snapshot of the left vortex dominance $(\mathrm{t}=5 \mathrm{~s})$ and the right vortex dominance $(\mathrm{t}=41 \mathrm{~s})$.

\section{CFD}

\section{Aerodynamics Simulations}

In order to assess the validity of numerical predictions, aerodynamics simulations used a freestream velocity of $40 \mathrm{~m} / \mathrm{s}$, matching the conditions used in the experiments. Figure 12 presents base pressure data computed with both RANS and URANS techniques. The scale is the same as that used to present experimental results in Figure 3. The shape of the rear wake computed with RANS appears to be symmetrical, leading to an unphysical base pressure distribution of a circular pattern. It also fails to predict the ground plane effect and the range of base pressure is quite different from the experimental data seen in Figure 3. Although the URANS results are considered to be more representative than those obtained with RANS, the base pressure computed with URANS does not match experimental data either. The computed drag and lift coefficients are shown in Table 3. 
Table 3. Averaged Force Coefficients

\begin{tabular}{|l|l|l|l|}
\hline & Exp & RANS & URANS \\
\hline$C_{D}$ & 0.283 & 0.276 & 0.2566 \\
\hline$C_{L}$ & -0.1 & -0.18 & -0.1479 \\
\hline
\end{tabular}

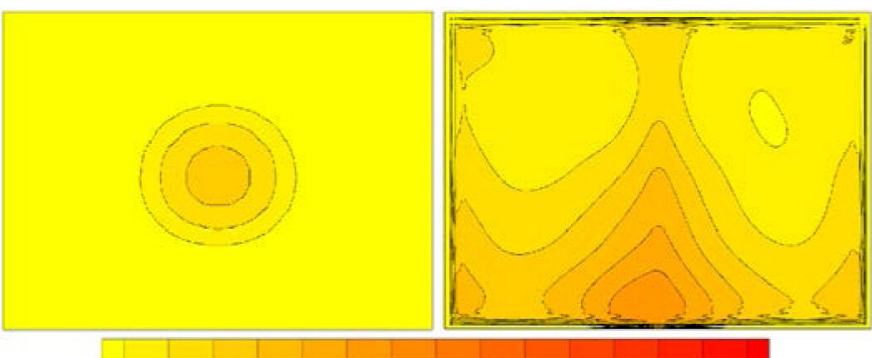

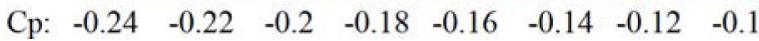

Figure 12. Base pressure computed with RANS (left) and URANS (right).

The failure of RANS to predict the base pressure is a disadvantage emphasized in numerous studies (see, for example, [36] ). One of the reasons for the discrepancy between URANS and experimental results might be the under prediction of bilateral instability in the wake. Figure 13 shows evidence of lateral flapping of the wake structure in the URANS simulation, but the computed vortices are around $0.65-0.75$ the base width, compared to the vortices seen in the experiments (Figure 4) where the vortex seems to occupy almost the whole width of the base. The flow therefore impinges onto the far edge, leading to the base pressure distribution shown in Figure 3. While URANS has not captured the aerodynamics exactly, which may require high fidelity methods such as DES or LES, it has recovered some of the unsteady behaviour seen in experiment.

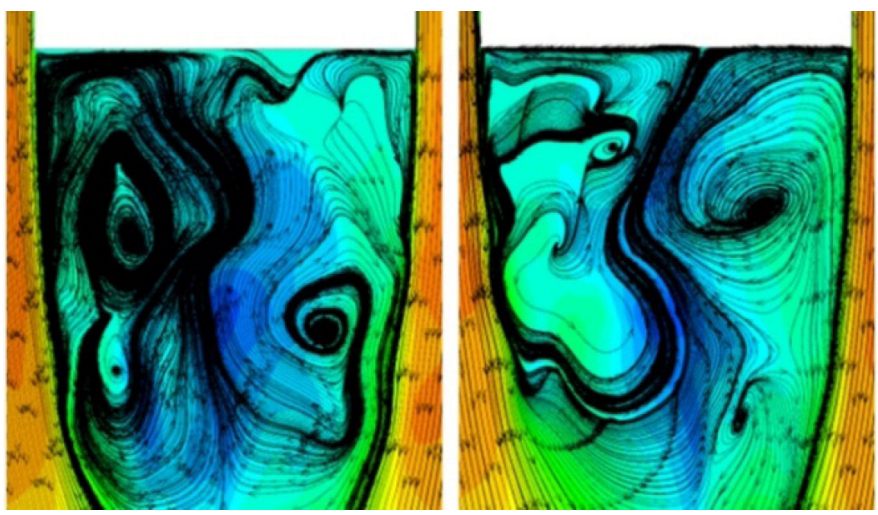

Figure 13. Horizontal unsteadiness of wake in $y$-x mid plane computed with URANS.

\section{Contamination Simulations with Particles of Constant Sizes}

Figures 14 to 16 present base contamination computed using RANS and URANS approaches using spray conditions chosen to match the 4.5 MPa case with air velocity equal to $30.5 \mathrm{~m} / \mathrm{s}$. To investigate the behaviour of particles of different sizes, in each case a uniform particle size is seeded into the computation: $102 \mu \mathrm{m}, 25 \mu \mathrm{m}$ and $4 \mu \mathrm{m}$. In the figures the base surface is coloured by the fraction of the total injected water mass. This allows information about the most contaminated areas to be inferred. The physical time computed is 3 seconds. Figure 17 shows the position of computational parcels to the rear of the body at instants during the URANS simulations. In this figure the parcels are coloured according to their velocity in the direction of the tunnel flow.

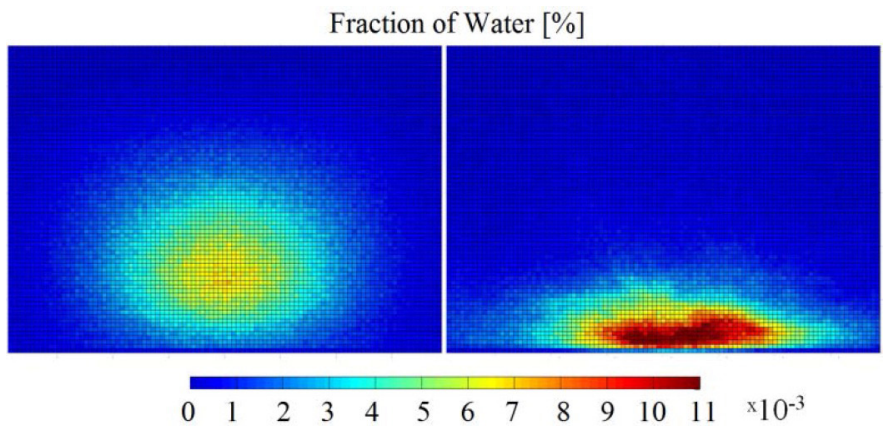

Figure 14. Computed base contamination using RANS (left) and URANS (right) with $102 \mu \mathrm{m}$ particles.

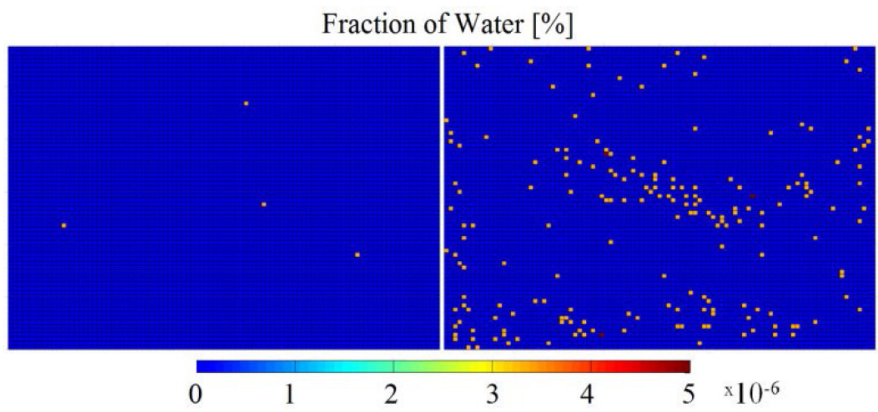

Figure 15. Computed base contamination using RANS (left) and URANS (right) with $25 \mu \mathrm{m}$ particles.

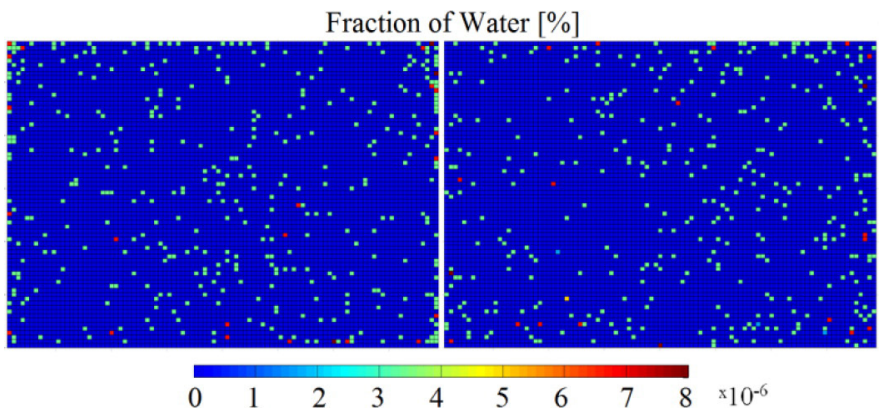

Figure 16. Computed base contamination using RANS (left) and URANS (right) with $4 \mu \mathrm{m}$ particles.
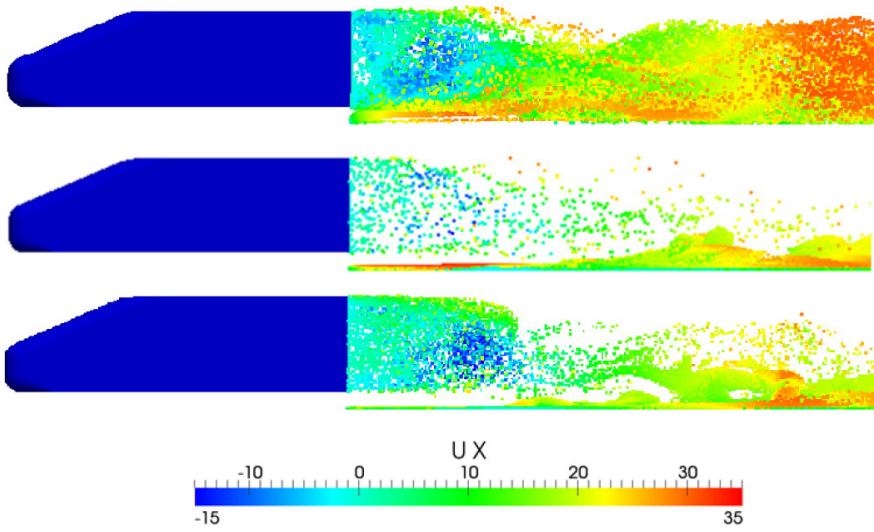

Figure 17. Particles of $102 \mu \mathrm{m}$ (top), $25 \mu \mathrm{m}$ (middle) and $4 \mu \mathrm{m}$ (bottom) behind the model, coloured according to x-velocity; Computed using URANS. 
According to the results shown in Figure 14, the particles of $102 \mu \mathrm{m}$ $(\mathrm{St}=6.57)$ have sufficient momentum to penetrate the wake close to the model surface. This is also achieved due to the high seeding angle. The aerodynamic forces subsequently force these particles towards the model's base surface. The pattern of contamination computed with both RANS and URANS resembles the pattern of their predicted base pressures. RANS predicts impingement of $102 \mu \mathrm{m}$ particles close to the base centre where the pressure is the highest. The particles computed with URANS follow the same trend and concentrate in the area of high base pressure (see Figure 14); This is consistent with observations made by Costelli [12].

Figure 15 presents the base contamination when $25 \mu \mathrm{m}$ particles are in use. Both RANS and URANS predict negligible contamination on the base. Nevertheless, there is a difference between the two approaches, which confirms Roettger's statement that the probability of a particle hitting the surface is greatly reduced when using time-averaged flow fields [14]. It can also be seen from Figure 17 that the spray of $25 \mu \mathrm{m}$ $(\mathrm{St}=0.4)$ particles gets advected away almost instantly upon injection. As a result, particles get entrained into the wake entirely due to aerodynamic forces about 1 meter away from the base.

As the particles become smaller $(4 \mu \mathrm{m}, \mathrm{St}=0.01)$, the distance between the base and the location at which they are entrained into the wake is reduced. This is because the momentum of $4 \mu \mathrm{m}$ particles is small and they are responsive to any changes in the airflow. As a result, larger amounts of $4 \mu \mathrm{m}$ particles get trapped in the wake compared to a $25 \mu \mathrm{m}$ particle case. However, only a fraction of these hit the base (see Figure 16). This is because these small particles do not possess enough momentum to reach the surface; making the particles recirculating in the wake behind the model rather than being deposited onto the surface.

Table 4 shows how much particle mass has impinged on the base in the RANS and URANS computations. Assuming that the percentage of the contaminant that hits the base is constant over time, the amount of contamination can be considered negligible for the cases which used $25 \mu \mathrm{m}$ and $4 \mu \mathrm{m}$ particles. A strong influence of particle size is seen in these results.

Table 4. Mass fraction that impinges the base

\begin{tabular}{|l|l|l|}
\hline \multirow{2}{*}{ Case } & \multicolumn{2}{|l|}{ Percentage of mass that impinges the base } \\
\cline { 2 - 3 } & RANS & URANS \\
\hline $102 \mu \mathrm{m}$ particles & $10.36 \%\left(5.31 \times 10^{-4} \mathrm{~kg}\right)$ & $7.84 \%\left(4.0 \times 10^{-4} \mathrm{~kg}\right)$ \\
\hline $25 \mu \mathrm{m}$ particles & $1.60 \times 10^{-5} \%\left(8.55 \times 10^{-10} \mathrm{~kg}\right)$ & $6.47 \times 10^{-4} \%\left(3.32 \times 10^{-8} \mathrm{~kg}\right)$ \\
\hline $4 \mu \mathrm{m}$ particles & $1.49 \times 10^{-3} \%\left(7.63 \times 10^{-8} \mathrm{~kg}\right)$ & $1.32 \times 10^{-3} \%\left(6.79 \times 10^{-8} \mathrm{~kg}\right)$ \\
\hline
\end{tabular}

\section{Contamination Simulations with Particles of Mixed Sizes}

A range of particle sizes to match that produced at a seeding pressure of $4.5 \mathrm{MPa}$ was used in RANS and URANS computations for a direct comparison with the experimentally obtained data. The physical time computed was 3 seconds at model scale. Although one may argue that the comparison of particle distribution from a simulation with that taken from a longer experiment is not accurate, we believe that the CFD result would not change much with additional time, as the CFD does not contain the physics responsible for the longer-time variation in the experiment. Although the density of particles on the surface and therefore the film thickness would increase, the general shape of contamination would remain relatively unchanged. This makes qualitative comparisons valid.

Figure 18 presents base contamination obtained with RANS and URANS approaches that used a complete distribution of particles. The particles are coloured by their size. Both RANS and URANS predict that amongst various particle sizes it is mostly large particles that reach the base. To make the qualitative comparison of CFD and experimental data easier, Figure 19 presents CFD results in terms of the mass of water that deposits on the rear surface of the model as a fraction of the total mass injected. This figure also shows the experimental data, which corresponds to the $4.5 \mathrm{MPa}$ test case.

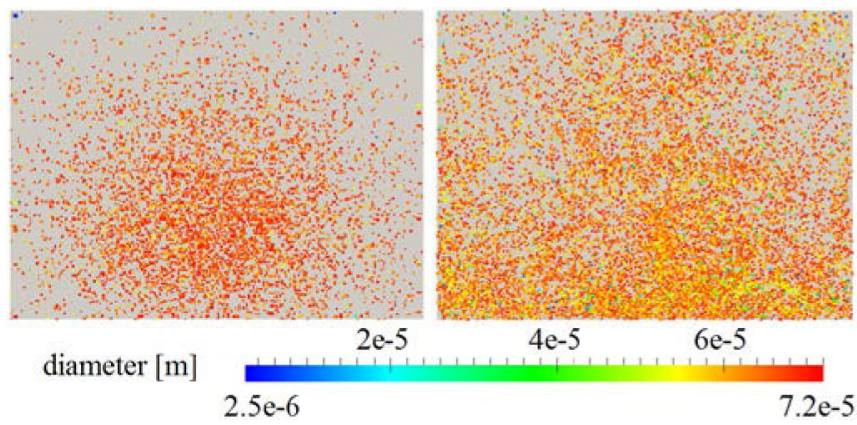

Figure 18. Computed base contamination using RANS (left) and URANS (right) with particles of mixed sizes.
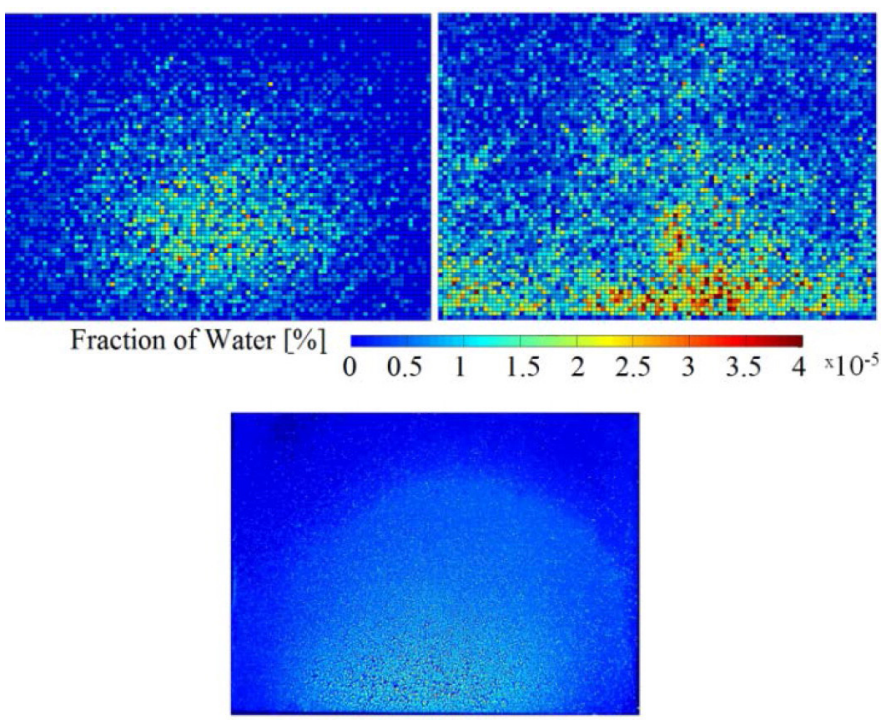

Figure 19. Computed base contamination using RANS (left) and URANS (middle) with particles of mixed sizes; Experimental results, $\mathrm{t}=15 \mathrm{~s}, 4.5 \mathrm{MPa}$ test case (right).

It can be seen that while the numerical data produced with RANS resembles experimental results, it still fails to match experimental data. Although it does predict base contamination of a circular pattern, the location of high contamination is very close to the centre of the base, whereas the experimental results show that the distribution is centred on the bottom edge of the base. The URANS approach, on the other hand, predicts that the centre of the contamination pattern is located towards the bottom of the base. This is a consequence of it capturing some large scale wake unsteadiness. However, the shape of contamination is wrong. All in all, even 
though the numerical results may resemble the experimental data to some extent, the agreement is not good. Any superficial agreement should be viewed with some caution as the base pressure distribution and the wake structure computed numerically are not correct.

Hence, while the URANS method is able to correctly capture some of the wake instability, it does not predict the full extent of this and this must affect the contamination pattern. Similarly, it predicts base pressure distribution better than the RANS approach, whilst still being in substantial error.

As a result, high-fidelity eddy-resolving methods such as the Lattice Boltzmann approach (as used in [1] [2] and []ㅡ), DES or LES [ $\underline{15}]$ may be necessary. For example, the LES results provided by Paschkewitz [15] showed more persistent and finer-scale structures behind a bluff body model; in turn, this led to different particle dispersion behaviour compared to URANS results. For instance, the LES results showed an increased vertical dispersion of particles. However the very long timescale of the bilateral instability in the wake observed in the experiment reported here (up to 40s) would make capturing this with an eddy-resolving method computationally very challenging.

As further consequence of failing to account for flow unsteadiness, even to the degree captured by URANS, is demonstrated in Figures $\underline{20}$ and 21 . The behaviour of particles in the wake behind the model predicted by URANS and RANS simulations are compared. The concentration of particles in the wake computed with RANS is much smaller than that computed with URANS, which again confirms the statement by Roettger regarding the probability of particles to reach the surface in a time-averaged flow field [14]. However, both approaches are consistent with regard to the size of particles seen in the wake. These are mainly large particles ranging from $60 \mu \mathrm{m}$ to $72 \mu \mathrm{m}$ and their fraction in the spray is only $4-5 \%$. It can be noted that the flow computed with URANS shows a slightly wider range of particle sizes deposited on the rear due to more particles being entrained by the unsteady wake. This is consistent with the observation by Paschkewitz in [15], who suggests that while the URANS may be sufficient for problems that involve large particles (with substantial inertia), high fidelity methods such as LES are necessary to accurately capture the dispersion behaviour of small, low inertia particles.

All the simulations in this work suggest that the size (and momentum) of the droplets plays a crucial role in determining whether particles are able to be entrained into the vehicle wake. This filtering of particle sizes passing into the wake suggests that knowledge of the particle size ranges likely to be encountered in a vehicle contamination simulation is likely to be crucial in accurately predicting likely contamination patterns. In turn, this shows the importance of reducing the uncertainty surrounding some of the spray parameters in the experiment, such as initial droplet velocity, which may affect results as might the neglect of breakup or coalescence of the droplets.

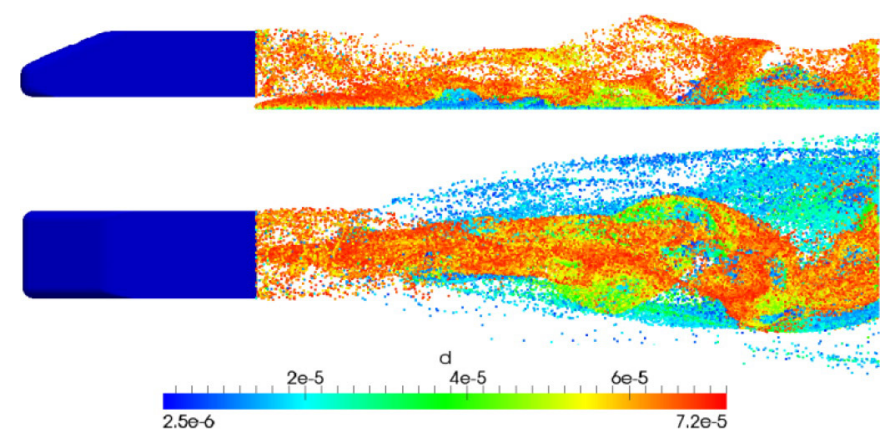

Figure 20. Particles of mixed sizes in a wake behind the model computed with URANS; side view (top) and top view (bottom).

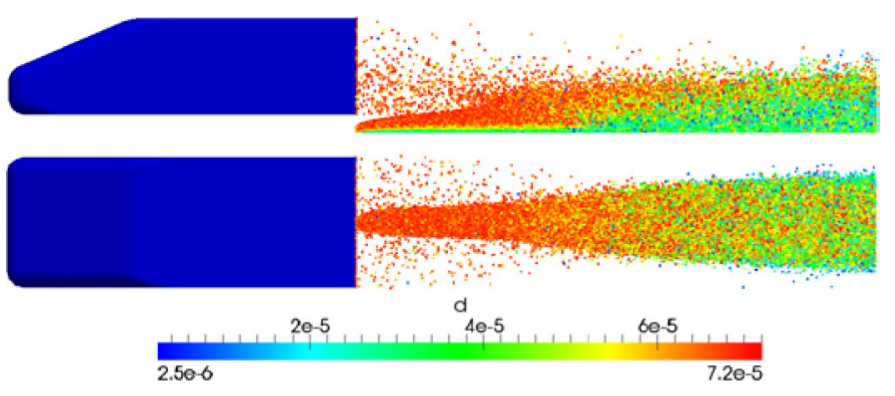

Figure 21. Particles of mixed sizes in a wake behind the model computed with RANS; side view (top) and top view (bottom).

\section{Conclusions}

An initial study of surface contamination with a standard representative model has been described. To author's best knowledge, this is the first attempt to use a simple test case, providing experimental data and simulations in this field. Experiments and CFD were used to analyse interaction of flow structures with droplets and how these interactions influence contamination on the rear surface of a Windsor body model. It was identified that for the current experimental set-up the droplets mostly impinge towards the bottom edge of the base. Differences were seen when the spray properties were varied by changing the spray nozzle pressures. In general a higher velocity and lower particle size, as produced by a higher nozzle pressure, led to a more rapid accumulation on the base and a more diffusive distribution resulting in contaminant deposited in the upper outboard of the base.

Computational analysis involved both RANS and URANS techniques together with Lagrangian particle tracking. It was seen that URANS was better able to predict the location of the centre of the contamination towards the bottom edge of the base. This suggests that inclusion of unsteady phenomenon is necessary to predict surface contamination. However the agreement between URANS and experiment is far from satisfactory. This is associated with the inability of steady or unsteady RANS to reproduce important turbulent structures of all scales which can affects particle behaviour. It should also be emphasized that the predicted aerodynamics data does not agree with experiments for either URANS and RANS and so any superficial agreement with experiment should be treated with caution. This study has shown that neither RANS nor URANS is suitable for simulating multiphase flows around bluff bodies, which is a point worth making given the still relatively wide usage of RANS. One of the conclusions of this preliminary study is that this class of 
multiphase flow must be treated as unsteady and a higher fidelity eddy resolving method such as LES (or DES) is essential and will be used next.

An investigation was performed into the influence of injected particle size. Particles with a Stokes number much higher than unity were found to more easily penetrate the wake. These particles have high momentum and, with a seeding angle of 45 degrees, enter the wake close to the base surface. They subsequently impinge on the base due to the reversed flow present in the wake, which turns them towards the surface. Intermediate sized particles are seen to be unable to penetrate into the wake and a low concentration of these is predicted to be found in both the wake and on the base. On the other hand, particles with a much smaller Stokes number are seen to be entrained into the wake, not due to their original momentum, but due to being captured up by the unsteady motion of the wake. However, once in the wake they are seen to be preferentially trapped in vortex structures; thus, they have a lower probability of reaching the surface as they do not possess enough momentum to exit these structures. It is also realized that the inability of URANS to accurately predict the mixing within the shear layer reduces the transport of smaller particles, potentially making the computational data a result of the model used rather than the physical transport mechanisms.

Nevertheless, this preliminary study does show that it is crucial to know the droplet size distribution present in the wake in order to correctly simulate vehicle base contamination. This is something that needs to be addressed in future work.

This work has deliberately chosen to use a vehicle body without wheels so as to consider rear contamination in the absence of wheel wakes. Including the effect of wheels (and their wakes) is the next step in this progressive programme of work. It is hoped that this will provide insight into the role of wheel wakes in rear surface contamination.

\section{References}

1. Gaylard, A., Pitman, J., Jilesen, J., Gagliardi, A. et al., "Insights into Rear Surface Contamination Using Simulation of Road Spray and Aerodynamics," SAE Int. J. Passeng. Cars - Mech. Syst. 7(2):673-681, 2014, doi:10.4271/2014-01-0610.

2. Jilesen, J., Gaylard, A., Duncan, B., Konstantinov, A. et al., "Simulation of Rear and Body Side Vehicle Soiling by Road Sprays Using Transient Particle Tracking," SAE Int. J. Passeng. Cars - Mech. Syst. 6(1):424-435, 2013, doi:10.4271/2013-011256.

3. Gaylard, A. and Duncan, B., "Simulation of Rear Glass and Body Side Vehicle Soiling by Road Sprays," SAE Int. J. Passeng. Cars - Mech. Syst. 4(1):184-196, 2011, doi: 10.4271/2011-01-0173.

4. Ashton M. and Baas P., 'Spray and Wind Buffeting from Heavy Vehicles: A Literature Review’, Wellington, New Zealand, 1998.

5. Watkins S., 'Spray from Commercial Vehicles: A Method of Evaluation and Results from Road Tests', in The Aerodynamics of Heavy Vehicles II; Trucks, Buses, and Trains, Browand F., McCallen R., and Ross J., Eds. Springer Berlin Heidelberg, 2009, pp. 387-402, doi:10.1007/978-3-540-85070-0-36.
6. Manser M., Koppa R., and Mousley P., 'Evaluation of Splash and Spray Suppression Devices on Large Trucks During Wet Weather', AAA Foundation for Traffic Safety, pp. 1-56, 2003.

7. Le Good, G. and Garry, K., "On the Use of Reference Models in Automotive Aerodynamics," SAE Technical Paper 2004-011308, 2004, doi:10.4271/2004-01-1308.

8. Rhode R. V, 'Some Effects of Rainfall on Flight of Airplanes and on Instrument Indications', 1941.

9. Dawley, M., "Aerodynamic Effects on Automotive Components," SAE Technical Paper 650134, 1965, doi:10.4271/650134.

10. Maycock G., 'The problem of water thrown up by vehicles on wet roads', in Road Research Laboratory Report No.4, Harmondsworth, 1966.

11. Weir D. H., Strange J. F., and Heffley R. K., 'Reduction of Adverse Aerodynamic Effects of Large Trucks Volume I', Federal Highway Administration Technical Report No. FHWARD-79-84, 1978.

12. Costelli, A., "Aerodynamic Characteristics of the Fiat UNO Car," SAE Technical Paper 140297, 1984, doi:10.4271/840297.

13. Yoshida M., Yamatani A., and China H., 'Prediction of dirt contamination on vehicle body surface', JSAE Review, vol. 19(3), pp. 257-262, doi: 10.1016/S0389-4304(98)00015-0, 1998.

14. Roettger S., Schulz M., Bartelheimer W., and Ertl T., 'Automotive Soiling Simulation Based On Massive Particle Tracing', in Proceedings of EG/IEEE TCVG Symposium on Visualization VisSym '01, 2001, pp. 309-317.

15. Paschkewitz J. S., 'A comparison of dispersion calculations in bluff body wakes using LES and unsteady RANS', Energy and Environment Directorate, Lawrence Livermore National Laboratory, no. UCRL-TR-218576, 2006.

16. Kuthada T. and Cyr S., 'Approaches to Vehicle Soiling', Progress in Vehicle Aerodynamics, Numerical methods. Renningen: Expert-Verlag, vol. IV, pp. 111-123, 2006.

17. Howell, J., Passmore, M., and Tuplin, S., "Aerodynamic Drag Reduction on a Simple Car-Like Shape with Rear Upper Body Taper," SAE Int. J. Passeng. Cars - Mech. Syst. 6(1):52-60, 2013, doi:10.4271/2013-01-0462.

18. Howell, J. and Le Good, G., "The Effect of Backlight Aspect Ratio on Vortex and Base Drag for a Simple Car-Like Shape," SAE Technical Paper 2008-01-0737, 2008, doi:10.4271/200801-0737.

19. Littlewood, R. and Passmore, M., "The Optimization of Roof Trailing Edge Geometry of a Simple Square-Back.," SAE Technical Paper 2010-01-0510, 2010, doi:10.4271/2010-01$\underline{0510 .}$.

20. Pavia, G., Passmore, M., and Gaylard, A., "Influence of Short Rear End Tapers on the Unsteady Base Pressure of a Simplified Ground Vehicle.," SAE Technical Paper 2016-01-1590, 2016, doi:10.4271/2016-01-1590.

21. Adrian R. J. and Westerweel J., 'Proper Orthogonal Decomposition', in Particle Image Velocimetry, Cambridge, 2011, pp. 470-480. 
22. Sirovich L., 'Turbulence and the Dynamics of Coherent Structures Part I: Coherent Structures*', Quarterly of Applied Mathematics, vol. XLV, no. 3, pp. 561-571, ISBN:9780521634199, 1987.

23. Sirovich L., 'Turbulence and the Dynamics of Coherent Structures Part II: Symmetries and Transformations*', Quarterly of Applied Mathematics, vol. XLV, no. 3, pp. 573582, ISBN:9780521634199, 1987.

24. Al-Garni, A., Bernal, L., and Khalighi, B., "Experimental Investigation of the Flow Around a Generic SUV," SAE Technical Paper 2004-01-0228, 2004, doi: 10.4271/2004-01$\underline{0228}$.

25. J.-Bouchet P., Delpech P., and Palier P., 'Wind tunnel simulation of road vehicle in driving rain of variable intensity', In 5th MIRA International Conference on Vehicle Aerodynamics.

26. 'Spray Nozzles - BETE.' [Online]. Available: http://www.bete. com/pdfs/BETE_MicroWhirl.pdf.

27. 'OpenFoam, v2.3.0.' <http://www.openfoam.com>, 2014.

28. Forbes D., Page G., Passmore M., and Gaylard A., 'Computational study of wake structure and base pressure on a generic SUV model.', The International Vehicle Aerodynamics Conference, 2014.

29. Yang W. B., Zhang H. Q., Chan C. K., and Lin W. Y., 'Large eddy simulation of mixing layer', Journal of Computational and Applied Mathematics, vol. 163, no. 1, pp. 311-318, 2004.

30. Davis P. L., Rinehimer A. T., and Uddin M., 'A Comparison of RANS-Based Turbulence Modeling for Flow over a WallMounted Square Cylinder', The University of North Carolina at Charlotte, Charlotte, 2012.

31. Gouesbet G. and Berlemont A., 'Eulerian and Lagrangian approaches for predicting the behaviour of discrete particles in turbulent flows', Progress in Energy and Combustion Science, vol. 25, pp. 133-159, doi:10.1016/S0360-1285(98)00018-5, 1999.

32. Barton I. E., 'Computation of Particle Tracks Over a BackwardFacing Step', Journal of Aerosol Science, vol. 26, no. 6, pp. 887-901, doi:10.1016/0021-8502(95)00018-8, 1995.

33. Schiller L. and Naumann A., 'Uber die grundlegenden berechnungen bei der schwerkraftaufbereitung', Zeitung des vereins deutscher ingenieure., pp. 77-318, 1933.

34. Gosman A. D. and Ioannides E., 'Aspects of Computer Simulation of Liquid-Fueled Combustors', Journal of Energy, vol. 7, no. 6, pp. 482-490, doi:10.2514/3.62687, 1983.

35. Paschkewitz J. S., 'Simulation of spray dispersion in a simplified heavy vehicle wake', Lawrence Livermore National Laboratory, Report No. UCRL-TR-218207, pp. 1- 20, 2006.
36. Davidson L. and Krajnovic S., 'Large-Eddy Simulation of the Flow Around a Ground Vehicle Body', Society of Automotive Engineers, Inc, no. 2001-01-0702, pp. 1-11, ISBN:2001-010702, 2001.

\section{Acknowledgments}

This work was supported by Jaguar Land Rover and the UK-EPSRC grant EP/K014102/1 as part of the jointly funded Programme for Simulation Innovation

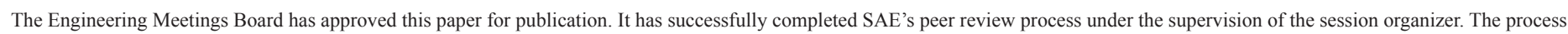
requires a minimum of three (3) reviews by industry experts.

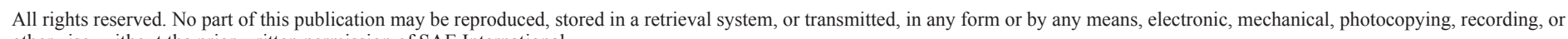
otherwise, without the prior written permission of SAE International.

Positions and opinions advanced in this paper are those of the author(s) and not necessarily those of SAE International. The author is solely responsible for the content of the paper.

ISSN 0148-7191

http://papers.sae.org/2016-01-1604 